\title{
Laboreal
}

Volume $3 \mathrm{~N}^{\circ} 1$ | 2007

Varia

\section{Pelas fendas do trabalho vivo : textos, contextos e atos na atividade de vigilância em saúde do trabalhador}

Por las hendiduras del trabajo vivo: textos, contextos y actos en la actividad de vigilancia en salud del trabajador

Par les failles du travail vivant : textes, contextes et actes dans l'activité du préventeur en santé du travailleur

Through the gaps of living work : texts, contexts and acts in the activity of workers' health surveillance

\section{Kátia Santorum}

\section{OpenEdition}

\section{Journals}

\section{Edição electrónica}

URL: http://journals.openedition.org/laboreal/12925

DOI: $10.4000 /$ laboreal. 12925

ISSN: 1646-5237

\section{Editora}

Universidade do Porto

\section{Refêrencia eletrónica}

Kátia Santorum, «Pelas fendas do trabalho vivo : textos, contextos e atos na atividade de vigilância em saúde do trabalhador », Laboreal [Online], Volume 3 NN$^{0} 1$ | 2007, posto online no dia 01 julho 2009, consultado o 24 setembro 2020. URL : http://journals.openedition.org/laboreal/12925 ; DOI : https:// doi.org/10.4000/laboreal.12925

Este documento foi criado de forma automática no dia 24 setembro 2020.

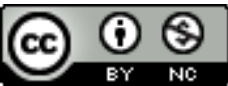

Laboreal está licenciado com uma Licença Creative Commons - Atribuição-NãoComercial 4.0 Internacional. 


\section{Pelas fendas do trabalho vivo: textos, contextos e atos na atividade de vigilância em saúde do trabalhador}

Por las hendiduras del trabajo vivo : textos, contextos y actos en la actividad de vigilancia en salud del trabajador

Par les failles du travail vivant : textes, contextes et actes dans l'activité du préventeur en santé du travailleur

Through the gaps of living work : texts, contexts and acts in the activity of workers' health surveillance

\section{Kátia Santorum}

\section{REFERÊNCIA}

Santorum, Katia. (2006). Pelas Fendas do Trabalho Vivo : textos, contextos e atos na atividade de Vigilância em Saúde do Trabalhador. Tese de Doutoramento. Rio de Janeiro : Escola Nacional de Saúde Pública Sérgio Arouca (ENSP) Fundação Oswaldo Cruz (FIOCRUZ)

\section{NOTA DO EDITOR}

Manuscrito recebido em : Fevereiro/2007

Aceite após peritagem em : Junho/2007 


\section{Introdução}

1 As reflexões aqui apresentadas decorrem da pesquisa de doutorado que contou com a orientação da Pesquisadora Jussara Brito, da ENSP. Teve como objetivo principal a análise da atividade de Vigilância em Saúde do Trabalhador (VST), no âmbito do Sistema Único de Saúde (SUS) brasileiro. A origem deste estudo situa-se na percepção de uma descontinuidade entre as ações no campo da saúde do trabalhador e os princípios que lhe orientam. Entre os conhecimentos acumulados e reflexões sobre essas ações de um lado e, de outro, os desdobramentos que a vida de cada dia solicita daqueles e daquelas que são responsáveis por executá-las.

2 Apesar dos avanços técnicos, políticos e legais, há impasses e atravessamentos no caminho trilhado por essa política pública, ao longo da implementação da Saúde do Trabalhador no SUS. A dinâmica de embates que marca seu percurso aponta a necessidade de criar dispositivos que contribuam para a legitimação e institucionalização desse campo de práticas. Assim, a Vigilância em Saúde do Trabalhador foi escolhida como tema da pesquisa, pela função estratégica que desempenha na busca de uma relação saudável da sociedade com o trabalho. É a entrada da Saúde Pública nos ambientes e processos produtivos.

O Programa de Saúde do Trabalhador (PST) da cidade de Volta Redonda, localizada no estado do Rio de Janeiro, foi o cenário de onde partiram as análises, sendo protagonistas do estudo os profissionais que compõem a equipe de VST deste Programa. A aproximação ao tema enfocou noções acumuladas no campo da Saúde do Trabalhador (ST), tais como a de saúde, trabalho e risco, colocando-as em diálogo com contribuições oriundas da Psicologia do Trabalho Italiana e Francesa, da Ergonomia da Atividade, da perspectiva Ergológica e da abordagem da Clínica da Atividade, especialmente no que convergem para o desenvolvimento da noção de atividade.

\section{Um processo de co-análise e co-elaboração da experiência : a propósito do dispositivo metodológico da autoconfrontação cruzada}

4 O principal dispositivo do qual lançamos mão foi a autoconfrontação cruzada (Clot, 1999, 2000 ; Faïta, 2005), que tem como recurso básico, imagens filmadas da atividade de trabalho. Mantendo o foco da intervenção em uma situação específica de trabalho, a autoconfrontação cruzada propõe ao(s) sujeito(s) a tarefa de elucidar para um outro, que pode ser tanto o pesquisador, formador ou um colega de trabalho que se ocupa da mesma atividade, e para si mesmo, as questões que surgem no desenvolvimento das atividades apresentadas, com a ajuda do vídeo.

5 Este dispositivo ao conformar diferentes contextos de análise produziu uma considerável pluralidade e riqueza em termos de possíveis pontos de vista que se debruçaram sobre a atividade. Os protagonistas desempenharam simultaneamente os papéis de espectadores, personagens, atores, autores e co-autores da atividade de vigilância e da atividade de análise. Deu passagem a muitas possibilidades de analisar, compreender, realizar ou não realizar na atividade de VST. Colocou em cena a necessidade de articulação com alguns dos conceitos que se apresentaram como ferramentas importantes para a análise dessa atividade tais como o conceito de gênero 
profissional (Clot, 1999 ; Clot \& Faïta, 2000), e de real da atividade (Clot, 1999; 2001), bem como o conceito de normas antecedentes (Schwartz, 2000). Observamos que esse dispositivo propiciou um espaço consistente para elaborar e formalizar a experiência na atividade de vigilância, configurando-se como um dispositivo de formação. Esta potencialidade do método em termos de desenvolvimento da atividade também foi compartilhada por nossos parceiros em análise

\section{Atos do trabalho vivo : pistas sobre o real da atividade de VST}

6 Observamos que as prescrições nessa atividade assumem um caráter amplo e multidefinido, apresentando-se mais com características de Normas Antecedentes, tal como definido por Schwartz (2000).

7 Identificamos que a abordagem do processo de trabalho, pelos vigilantes, enfoca predominantemente os aspectos físicos, químicos, mecânicos e biológicos da relação dos sujeitos com o trabalho, ou seja, o ponto de vista das condições de trabalho, colocando no centro da vigilância em saúde do trabalhador, os agravos, doenças e acidentes. Os determinantes são perseguidos através de parâmetros mensuráveis, com vistas a controlálos ou eliminá-los. Essas reflexões remetem inevitavelmente ao sentido que vem sendo atribuído à noção de saúde nesse referencial.

8 Contrastando com essa realidade, encontramos um dos princípios básicos que constituem o campo da ST, relativo à importância e centralidade dos conhecimentos oriundos da experiência e do ponto de vista dos trabalhadores. Observamos que esse princípio (norma antecedente) embora eminentemente presente e considerado importante pelos vigilantes, parece frágil, carecendo de estratégias de operacionalidade, parecendo mesmo não encontrar sustentabilidade para ser efetivado por eles, durante as ações.

9 Essa observação envia a características que parecem delinear um gênero profissional (Clot, 1999 ; Clot \& Faïta, 2000) de VST. Entre elas, uma preocupação entre os vigilantes, de buscar respaldar sua tomada de posição durante as ações, em bases sólidas e inquestionáveis. A discussão que propomos acerca desses elementos comparece articulada a análise que fazemos de uma dimensão mais ampla onde esta prática se inscreve. Chamamos atenção para o que consideramos como uma fragilidade do respaldo institucional às ações de VST, a qual identificamos vinculada às relações capital-trabalho, na qual operam estes atores. Merece atenção o modo como cada um busca lidar com a referida fragilidade do respaldo institucional no curso da ação e os impactos que essa situação tem sobre o poder de agir nesse coletivo. Como põe à prova os personagens, desafiandoos a encontrar possíveis, apesar dela. A tornar a situação vivível. Essa nos pareceu, entre tantas outras, uma pista importante a perseguir : até que ponto, e com quais repercussões para seus protagonistas, resistirá um gênero cujo respaldo institucional é frágil ?

10 Ao colocarmos em circulação a noção de inatividade imposta (Clot, 1999), surgem importantes elaborações feitas pelos vigilantes sobre as relações de poder que identificam no setor público de saúde que implicam diretamente nas margens de autonomia em relação à atividade. As sucessivas alternâncias na administração pública, 
por exemplo, indicam possíveis impactos à política municipal de saúde do trabalhador, e conseqüentemente à saúde daqueles responsabilizados pela sua execução cotidiana.

11 Observamos que aquilo que cada um fala, como fala e com quem fala, produz efeitos no curso da ação. Esses efeitos se fazem sentir através das reações dos colegas vigilantes e da receptividade ou não dos trabalhadores e dos empregadores. Pensamos que isso tenha implicações na própria eficácia da ação. Eficácia, que nesta atividade vai se desenhando como uma eficácia sempre relativa, desde que colocados em perspectiva os diferentes objetivos que se deve, que se pretende, que se deseja, que se necessita e que se pode perseguir em seu curso.

Essa pista aponta para a importância da atividade de linguagem, que é um recurso fundamental na atividade de vigilância. Tal como evidenciado por Schwartz (2003) e Clot (1999) pudemos perceber que a linguagem nesse contexto não é apenas um meio de expressão. Ela é uma atividade em si mesma. Paradoxalmente, tal atividade, fundamental nesse ofício, parece encontrar-se interditada. A controvérsia entre os profissionais que compõem a equipe de vigilância, condição importante da atividade, que permite renovar e fortalecer o gênero profissional (Clot, 1999) o debate, as variantes, as criações, os confrontos, parecem interditados nesse ofício. São pistas que nos levam a pensar nas repercussões desta situação para os vigilantes, sobre o poder de agirem sobre si mesmos e sobre o meio de trabalho.

Entre os sentidos que se produzem, sobre o ato de vigiar, nessa atividade, sobressai aquele que o associa à aplicação de conhecimentos já cristalizados no que tange a prevenção de riscos e comprovação de hipóteses previamente formuladas. Fica na penumbra o potencial dessa atividade relativo à produção de conhecimentos no momento mesmo das ações. Esse aspecto merece atenção, posto que o trabalho dos vigilantes implica a defesa de determinados posicionamentos sobre o que é descoberto por eles na atividade de vigilância. Isso significa atentar para a importância da construção de meios que possibilitem elaborar as descobertas feitas na atividade, as quais não se deixam compreender através de abordagens quantitativas ou epidemiológicas. Isso aponta para a necessidade de criação de procedimentos que 'autorizem' essas descobertas. Contracenando silenciosamente com os saberes-fazer de prudência (Cru \& Dejours, 1983) desenvolvidos pelos vigilantes para fazer face à convivência com os riscos à sua própria saúde no curso das ações, suspeitamos que estejam, no outro pólo envolvido nessa atividade, os saberes-fazer de prudência, dos trabalhadores com os quais os vigilantes interagem. Essa pode ser uma região em que nossos diversos personagens parecem ora encontrar-se, ora desencontrar-se num complexo labirinto. Esperamos que essa investigação contribua para ampliar as possibilidades de compreender essa atividade e também no aprofundamento da reflexão sobre a necessidade de utilizarmos dispositivos que permitam abrir e transitar pelas fendas do trabalho vivo, voltando-se para a elaboração coletiva da experiência de trabalho. Buscar torná-la disponível à construção de novos modos de fazer e de dizer no cotidiano das ações que permitam um engajamento singular-coletivo dos protagonistas de modo que o objetivo de promoção da saúde que perseguem para os outros trabalhadores esteja em sintonia com a promoção de sua própria saúde. 


\section{BIBLIOGRAFIA}

Clot, Y. (1999). La fonction psychologique du travail. Paris : PUF.

Clot, Y. (2001).Clinique du travail, clinique du réel. Le journal des psychologues, 185, 48-51.

Clot, Y. \& Faïta, D. (2000).Genres et styles en analyse du travail. Travailler, 4, 7-43.

Cru, D. \& Dejours, C. (1983). Les savoirs-faire de prudence dans lês métiers du bâtiment. Les Cahiers Médico-Sociaux, 3, 239-247.

Faïta, D. (2005). Análise Dialógica da Atividade Profissional. Rio de Janeiro : Imprinta Express.

Jean, R. (2001). Sobre o agir ergológico. Trabalho apresentado no COLÓQUIO ALAIN WISNER E AS TAREFAS DO PRESENTE, 9 e 10 de março de 2001, Université de Provence, INÉDITO (trad. Ana Luiza Telles). Schwartz, Y. (2000). Le paradigme ergologique ou un métier de philosophe. Toulouse : Octarès.

\section{AUTOR}

\section{KÁTIA SANTORUM}

Universidade de Santa Cruz do Sul / RS Rua 28 de Setembro 16 / 701

katiasan@terra.com.br 